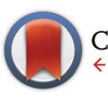

CrossMark \& click for updates

Cite this: Dalton Trans., 2016, 45 16653

Received 6th June 2016,

Accepted 24th August 2016

DOI: $10.1039 / c 6 d t 02258 \mathrm{~h}$

www.rsc.org/dalton

\title{
Single ion magnets based on lanthanoid polyoxomolybdate complexes $\uparrow$
}

\author{
José J. Baldoví, $\hbar^{a}$ Yan Duan, $\hbar^{\mathrm{a}}$ Carlos Bustos, ${ }^{\mathrm{b}, \mathrm{c}}$ Salvador Cardona-Serra, ${ }^{\mathrm{d}}$ \\ Pierre Gouzerh, ${ }^{C}$ Richard Villanneau, ${ }^{C}$ Geoffrey Gontard, ${ }^{C}$ Juan M. Clemente-Juan, ${ }^{\text {a }}$ \\ Alejandro Gaita-Ariño, *a Carlos Giménez-Saiz, ${ }^{\star a}$ Anna Proust*c and \\ Eugenio Coronado*a
}

\begin{abstract}
Polyoxometalate (POM) chemistry has recently offered excellent examples of single ion magnets (SIMs) and molecular spin qubits. Compared with conventional coordination compounds, POMs provide rigid and highly symmetric coordination sites. However, all POM-based SIMs reported to date exhibit a very limited range of possibilities for chemical processability. We present herein two new families of POM-based SIMs which are soluble in organic solvents: $\left[\mathrm{Ln}\left(\beta-\mathrm{Mo}_{8} \mathrm{O}_{26}\right)_{2}\right]^{5-}\left\{\mathrm{Ln}{ }^{\prime \prime \prime}=\mathrm{Tb}, \mathrm{Dy}, \mathrm{Ho}, \mathrm{Er}, \mathrm{Tm}\right.$ and $\mathrm{Yb}\}$ and the functionalised POMs $\left[\mathrm{Ln}\left\{\mathrm{MO}_{5} \mathrm{O}_{13}(\mathrm{OMe})_{4} \mathrm{NNC}_{6} \mathrm{H}_{4}-p-\mathrm{NO}_{2}\right\}_{2}\right]^{3-}\left\{\mathrm{Ln}{ }^{\prime \prime \prime}=\mathrm{Tb}, \mathrm{Dy}, \mathrm{Ho}, \mathrm{Er}, \mathrm{Yb}\right.$ and $\mathrm{Nd}$ \}. In addition, these two families represent the first SIMs based on polyoxomolybdates. A magnetostructural analysis of these families is presented, which is based on an effective crystal field model, and compared with the results reported in analogous lanthanoid SIMs based on polyoxotungstates.
\end{abstract}

\section{Introduction}

The main goal of spintronics is the active manipulation of the electron spin degrees of freedom in solid-state systems for carrying information. ${ }^{1,2}$ Spintronic systems have experienced a rapid development and currently are used in a range of applications, including read-heads devices and non-volatile magnetic memories (MRAM). ${ }^{3,4}$ Extraordinary potential for these systems is expected for the fabrication of spin-transfer nano-oscillators (STNOs) ${ }^{5}$ and quantum computers. $^{6-8}$ The progress of molecular electronics and molecular magnetism has led to the emergence of a new field known as molecular spintronics, ${ }^{9,10}$ which combines the ideas and concepts of spintronics with the singular possibilities offered by molecular electronics and molecular magnetism to develop a second generation of spintronic devices. ${ }^{11-14}$

\footnotetext{
${ }^{a}$ Instituto de Ciencia Molecular (ICMol), Universidad de Valencia, C/Catedrático José Beltran, 2, E-46980 Paterna, Spain. E-mail: alejandro.gaita@uv.es,

carlos.giménez@uv.es, eugenio.coronado@uv.es

${ }^{b}$ Facultad de Ciencia, Instituto de Química, Campus Isla Teja, Universidad Austral de Chile, Valdivia, Chile

${ }^{c}$ Sorbonne Universites, UPMC-Paris 06, UMR 8232, Institut Parisien de Chimie Moléculaire, 4 Place Jussieu, F-75005 Paris, France. E-mail: anna.proust@upmc.fr ${ }^{d}$ Trinity College Dublin, College Green, Dublin 2, Ireland

$\dagger$ Electronic supplementary information (ESI) available: Elemental analysis results; IR spectra; crystal structure determination details; magnetic properties. CCDC 1446092-1446097 (for $\mathrm{LnMo}_{16}$ ) and 1482838-1482842 (for $\mathrm{LnMo}_{10}$ ). For ESI and crystallographic data in CIF or other electronic format see DOI: 10.1039/ c6dt02258h

$\$$ Both authors contributed equally.
}

A particularly challenging area within this field is that of single-molecule spintronics, which intends to use individual molecules as main components of spintronic devices. In this context, single-molecule magnets $(\mathrm{SMMs})^{15}$ have been proposed as promising candidates. ${ }^{16-18}$ These systems, which represent the limit of miniaturization of nanomagnets, are between the most complex magnetic entities, exhibiting slow relaxation of the magnetization ${ }^{19}$ and magnetic hysteresis ${ }^{20}$ at liquid-helium temperatures. Moreover, they may also present quantum phenomena from purely molecular origin. ${ }^{21-24}$ In this context, SMMs based on mononuclear lanthanide complexes deserve a special attention..$^{25,26}$ The first example of this class of molecular nanomagnets, also known as single-ion magnets (SIMs), was reported by Ishikawa and co-workers in the series with general formula $\left[\mathrm{LnPc}_{2}\right]^{-}$, where lanthanoid ions are sandwiched between two phthalocyaninato moieties displaying a square-antiprismatic $D_{4 \mathrm{~d}}$ symmetry. ${ }^{27}$ Derivatives closely related to this family include the oxidised terbium phthalocyaninato complex $\left[\mathrm{TbPc}_{2}\right]^{0}$. This system, besides its "double-decker" structure which favours adsorption on surfaces, is electrically neutral. This feature facilitates its sublimation under UHV conditions. The processability of lanthanoid phthalocyaninato complexes has allowed a series of breakthroughs including the realization of molecular/supramolecular spin valves ${ }^{28,29}$ and the electrical control of nuclear spin qubits. $^{30,31}$ Indeed, sublimable lanthanoid complexes have demonstrated a great potential in molecular spintronics. Among the few sublimable lanthanoid-based systems reported so far, we can highlight the trinuclear $\mathrm{Tb}^{3+}$ complex 
$\mathrm{Tb}_{3}(\mathrm{OQ})_{9}$ (OQ = quinolinato), where spin-polarised hopping transport has been realised. ${ }^{32}$ It has also been proposed as a model system for quantum error correction in quantum computing. ${ }^{33}$

A second series of SIMs is that provided by polyoxometalate (POM) chemistry, ${ }^{34}$ a class of systems that has produced a number of conventional SMMs. ${ }^{35,36}$ In this case, mononuclear lanthanoid complexes encapsulated by POMs have produced key examples of spin qubits for quantum computing. Indeed, extended quantum coherence was recently achieved on concentrated samples of the holmium derivative of the series $\left[\mathrm{Ln}\left(\mathrm{W}_{5} \mathrm{O}_{18}\right)_{2}\right]^{9-}$ (in short $\left.\mathrm{LnW}_{10}\right)$ through the use of atomic clock transitions. ${ }^{37}$ Employing a different strategy, a large number of coherent manipulations was realised in the $\mathrm{Gd}^{3+}$ derivative $^{38}$ of the $\left[\mathrm{LnP}_{5} \mathrm{~W}_{30} \mathrm{O}_{110}\right]^{12-}$ series (in short $\mathrm{LnW}_{30}$ ). ${ }^{39}$ Within the same POM family, current rectification was achieved in a single molecule diode of $\mathrm{DyW}_{30}{ }^{40}$ Still, the incorporation of these molecular inorganic polyanions onto surfaces or its anchoring to electrodes have been limited by their poor solubility in organic solvents and by their difficult functionalization with organic ligands.

Here, we have prepared two families of POM-based mononuclear lanthanide complexes with a rigid square antiprism structure, analogous to that of $\mathrm{LnW}_{10}$, which overcome these processing limitations. The first family is formulated as $\left[\mathrm{Ln}\left(\beta-\mathrm{Mo}_{8} \mathrm{O}_{26}\right)_{2}\right]^{5-}$ (in short, $\left.\mathrm{LnMo}_{16}\right),\left\{\mathrm{Ln}^{\mathrm{III}}=\mathrm{Tb}, \mathrm{Dy}, \mathrm{Ho}, \mathrm{Er}\right.$, $\mathrm{Tm}$ and $\mathrm{Yb}\}$ and consists of a lanthanide ion trapped by two $\left[\beta-\mathrm{Mo}_{8} \mathrm{O}_{26}\right]^{4-}$ moieties. $^{41}$ The second family is formulated as $\left[\mathrm{Ln}\left\{\mathrm{Mo}_{5} \mathrm{O}_{13}(\mathrm{OMe})_{4} \mathrm{NNC}_{6} \mathrm{H}_{4}-p-\mathrm{NO}_{2}\right\}_{2}\right]^{3-}$ (in short, $\mathrm{LnMo}_{10}$ ), $\left\{\mathrm{Ln}^{\mathrm{III}}=\mathrm{Tb}, \mathrm{Dy}, \mathrm{Ho}, \mathrm{Er}, \mathrm{Yb}\right.$ and $\left.\mathrm{Nd}\right\}$. In this cases the lanthanide ion is trapped by a functionalised POM based on a lacunary Lindqvist-type pentamolybdate. ${ }^{42}$

\section{Results and discussion}

\section{Solubility and stability}

LnMo $_{16}$ series. The $\mathrm{LnMo}_{16}$ series are very soluble in acetone, acetonitrile and benzonitrile. Their derivatives are insoluble in methanol, ethanol, dichloromethane or chloroform, giving rise to colorless solutions. The structural integrity of the POMs in solution is kept as long as the solvents are dried, as shown by electrospray ionization for acetonitrile solutions (see Fig. S6†). Wet solvents, however, give rise to yellow solutions, evidencing decomposition.

$\mathbf{L n M o}_{10}$ series. Owing to the structural analogy between the $\left[\mathrm{Mo}_{5} \mathrm{O}_{13}\left(\mathrm{OCH}_{3}\right)_{4} \mathrm{NNC}_{6} \mathrm{H}_{4}-p-\mathrm{NO}_{2}\right]^{3-}$ units with their nitrosyl $\left[\mathrm{Mo}_{5} \mathrm{O}_{13}\left(\mathrm{OCH}_{3}\right)_{4}(\mathrm{NO})\right]^{3-}$ analogues, one could a priori expect the transformation of the $\mathrm{LnMo}_{10}$ family of compounds in other solvents than methanol, in which they are synthesised. However they proved to be unexpectedly stable in several organic solvents at least at room temperature. Indeed, they are soluble and can be recrystallised in acetonitrile and chlorinated solvents (chloroform or dichloromethane) without noticeable decomposition, at the difference of their nitrosyl analogues. $^{43}$ The combination of the stability and solubility properties of these compounds (the solution we used for their recrystallization are about $10^{-2}$ mol L ${ }^{-1}$ ) make them particularly interesting in the frame of their processing and utilization in nanodevices.

\section{Crystal structures}

LnMo $_{16}$ series. This family of compounds crystallise in two different space groups: monoclinic $\left(P 2_{1} / c\right)$ for $\mathrm{Tb}^{3+}$ and orthorhombic $(\mathrm{Pbca})$ for the rest of the series. Because of the rigidity of the POM, this difference in the crystallographic space group is in practice not noticeable in the vicinity of lanthanide ion. Thus, in all cases the structure exhibits the presence of a lanthanide ion sandwiched between two $\left[\beta-\mathrm{Mo}_{8} \mathrm{O}_{26}\right]^{4-}$ units. The lanthanide ions are coordinated by the eight terminal oxygen atoms coming from the two octamolybdate units giving rise to an eight-fold square antiprismatic coordination (Fig. 1). The structural parameters concerning the lanthanide coordination sphere are listed in Table 1 . Details of the crystal structure determination and crystallographic parameters (Table S1) are given in the ESI. $\dagger$

$\mathbf{L n M o}_{10}$ series. As in the case of the $\mathrm{LnMo}_{16}$ series, these complexes display a weakly distorted square antiprism geometry, in which the central $\mathrm{Ln}^{3+}$ cation interacts with two $\left[\mathrm{Mo}_{5} \mathrm{O}_{13}(\mathrm{OMe})_{4}\left(\mathrm{NNC}_{6} \mathrm{H}_{4}-p-\mathrm{NO}_{2}\right)\right]^{3-}$ units playing the role of
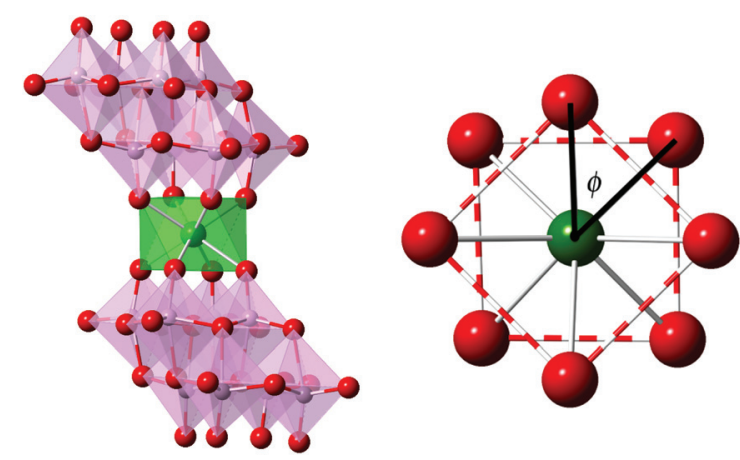

Fig. 1 (Left) Polyhedral and ball-and-stick representation of $\mathrm{LnMo}_{16}$ series and (right) projection of the coordination sphere showing the square-antiprismatic coordination site.

Table 1 Structural parameters concerning the lanthanide coordination sphere

\begin{tabular}{|c|c|c|c|c|c|c|}
\hline & \multicolumn{3}{|l|}{$\mathrm{LnMo}_{16}$} & \multicolumn{3}{|l|}{$\mathrm{LnMo}_{10}$} \\
\hline & $d_{\mathrm{pp}}{ }^{a}(\AA)$ & $d_{\text {in }}^{b}(\AA)$ & $\varphi^{c}\left({ }^{\circ}\right)$ & $d_{\mathrm{pp}}^{a}(\AA)$ & $d_{\text {in }}^{b}(\AA)$ & $\varphi^{c}\left({ }^{\circ}\right)$ \\
\hline $\mathrm{Tb}$ & $2.604(13)$ & $2.853(15)$ & $40.2(5)$ & $2.661(8)$ & $2.816(8)$ & $44.1(2)$ \\
\hline Dy & $2.552(18)$ & $2.844(18)$ & 44.1(5) & $2.640(6)$ & $2.797(6)$ & $44.2(2)$ \\
\hline Ho & $2.553(10)$ & $2.825(10)$ & $44.3(3)$ & $2.638(5)$ & $2.786(5)$ & $39.2(7)$ \\
\hline Er & $2.551(11)$ & $2.819(11)$ & $44.2(3)$ & $2.614(6)$ & $2.783(6)$ & $40.0(6)$ \\
\hline $\mathrm{Tm}$ & $2.506(14)$ & $2.818(14)$ & 44.1(4) & - & - & - \\
\hline $\mathrm{Yb}$ & $2.506(14)$ & $2.796(14)$ & $44.3(4)$ & $2.585(6)$ & $2.759(6)$ & $39.3(7)$ \\
\hline
\end{tabular}

${ }^{a} d_{\mathrm{pp}}$ defines the average distance between two oxygen based square planes. ${ }^{b} d_{\text {in }}$ is the average $\mathrm{O}-\mathrm{O}$ distance within the oxygen-based square planes. ${ }^{c} \varphi$ is defined as the relative orientation between the two squares defined by the coordinating oxygen atoms. 


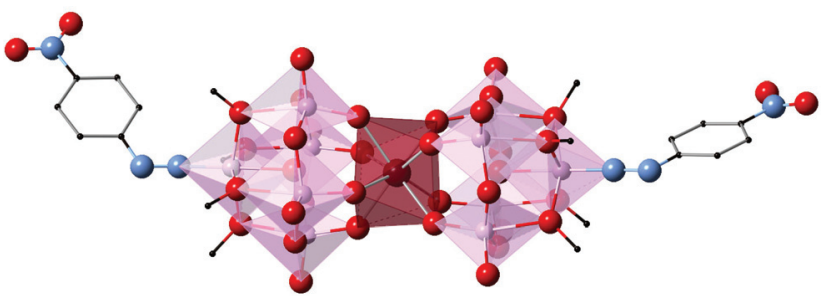

Fig. 2 Polyhedral and ball-and-stick representation of the $\mathrm{LnMo}_{10}$ series.

planar tetradentate ligands, and providing an eight-coordination environment. The structural parameters concerning the lanthanide coordination sphere are listed in Table 1. The geometrical parameters of this series are comparable to those observed for the nitrosyl derivatives $\left[\mathrm{X}\left\{\mathrm{Mo}_{5} \mathrm{O}_{13}(\mathrm{OMe})_{4}(\mathrm{NO})\right\}_{2}\right]^{n-}$ $\left\{\mathrm{X}=\mathrm{Ca}^{2+}, \mathrm{Sr}^{2+}, \mathrm{Ba}^{2+}, \mathrm{Ce}^{3+}, \mathrm{Eu}^{3+}\right.$ and $\left.\mathrm{Bi}^{3+}\right\},{ }^{44}$ thus indicating a slightly distorted $D_{4 \mathrm{~d}}$ geometry. The $\mathrm{TbMo}_{10}$ crystal structure is shown in Fig. 2. Details of the crystal structure determination and crystallographic parameters (Table S2) are provided in the ESI. $\dagger$

\section{Magnetic properties}

LnMo $_{16}$ series. A simultaneous fit was performed on the four magnetic susceptibility curves of the $\mathrm{Tb}^{3+}, \mathrm{Dy}^{3+}, \mathrm{Ho}^{3+}$ and $\mathrm{Er}^{3+}$ derivatives of this series using an effective crystal field approach (REC model; see section on experimental methods for details). The determined two parameters were tested by applying them to the real coordinates of the $\mathrm{Tm}^{3+}$ and $\mathrm{Yb}^{3+}$ derivatives. The predicted magnetic behaviour shows a very good agreement with the experimental data (Fig. 3).

The most satisfactory agreement was obtained when the radial displacement $\left(D_{\mathrm{r}}\right)$ equals $0.72 \AA$ and the effective charge $\left(Z_{\mathrm{i}}\right)$ is 0.253 . If we compare the obtained parameters with the ones extracted in the families $\operatorname{LnW}_{10}$ and $\left[\operatorname{Ln}\left(\beta_{2}-\mathrm{SiW}_{11} \mathrm{O}_{39}\right)_{2}\right]^{13-}$

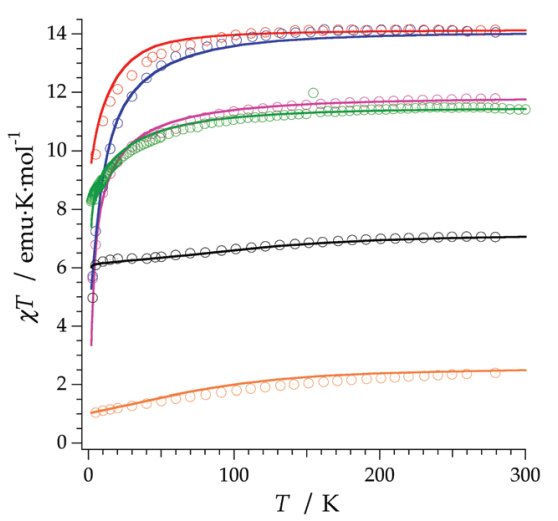

Fig. 3 Temperature-dependent magnetic susceptibility of the series $\mathrm{LnMO}_{16}$ and theoretical calculations using the REC model: $\mathrm{Dy}^{3+}$ (red), $\mathrm{Ho}^{3+}$ (blue), $\mathrm{Tb}^{3+}$ (pink), $\mathrm{Er}^{3+}$ (green), $\mathrm{Tm}^{3+}$ (black), $\mathrm{Yb}^{3+}$ (orange). Markers give experimental data under a magnetic field of $1000 \mathrm{Oe}$, and solid lines theoretical results: fits for $\mathrm{Tb}^{3+}-\mathrm{Er}^{3+}$ and predictions for $\mathrm{Tm}^{3+}$ and $\mathrm{Yb}^{3+}$. (in short: $\mathrm{LnW}_{22}$ ), ${ }^{45}$ the radial displacement is smaller in this case. This means that the effective point charge needs a smaller covalent correction to produce an adequate relation between the crystal-field parameters that describe the experimental data. This difference can be related to the different Pauling electronegativity of the Mo and W atoms (2.16 and 2.36 respectively). ${ }^{46}$ The larger difference in electronegativity between Mo (2.16) and $\mathrm{O}$ (3.44) enhances the ionic character of the Mo-O bonding and also the coordination bond Ln-O.

The resulting energy levels for all the series are reported in the ESI (Fig. S10 $\dagger$ ). A general trend for $\mathrm{LnMo}_{16}$ compared with $\mathrm{LnW}_{10}$ and $\mathrm{LnW}_{22}$ is a slightly larger crystal field splitting. In average, the Ln-O distance is practically identical in both series, e.g. in $\operatorname{ErW}_{10}$ and $\operatorname{ErMo}_{16}(2.367(7) \AA$ and 2.367(3) $\AA$ ). This would mean that polyoxomolybdates tend to produce a slightly stronger ligand field splitting compared with polyoxotungstates at a given metal-ligand distance. For a deeper analysis of the compounds that exhibit SMM properties in both families, the Stark sublevels of the $\mathrm{HoMo}_{16}$ and $\mathrm{ErMo}_{16}$ derivatives are plotted in Fig. 4. Regarding the lower states wave functions, one can observe that in the case of the $\mathrm{HoMo}_{16}$ the ground state is defined by a mixture of $47 \%$ of $\mid+4>$ and $47 \%$ of $\mid-4>$. In this case, the crystal field operators enable a quantum tunnelling splitting between wave functions with a strong mixture of $M_{J}$ components, and thus in absence of an external magnetic field no blocking of the magnetic moment is to be expected. Nevertheless when a longitudinal external field is applied, the purity of the $M_{J}=+4$ and $M_{J}=-4$ is recovered and thus, relaxation via tunnelling is cancelled and a blocking of the magnetization is possible. For $\mathrm{ErMo}_{16}$ the wave function for the ground state appears to be $M_{J}=$ $0.78| \pm 1 / 2>+0.12| \pm 13 / 2>$ with two states lying closely above it (at about 1.6 and $3.7 \mathrm{~cm}^{-1}$ ). Those are described by $M_{J}=$ $0.78 \mid \pm 15 / 2>-$ marked in red in Fig. $4-$ and $M_{J}=0.74 \mid \pm 13 / 2>+$ $0.15 \mid \pm 15 / 2>$ respectively. The low energy difference between the ground and the first excited state (and even the second) is definitively below the precision of the method. Also, thermal

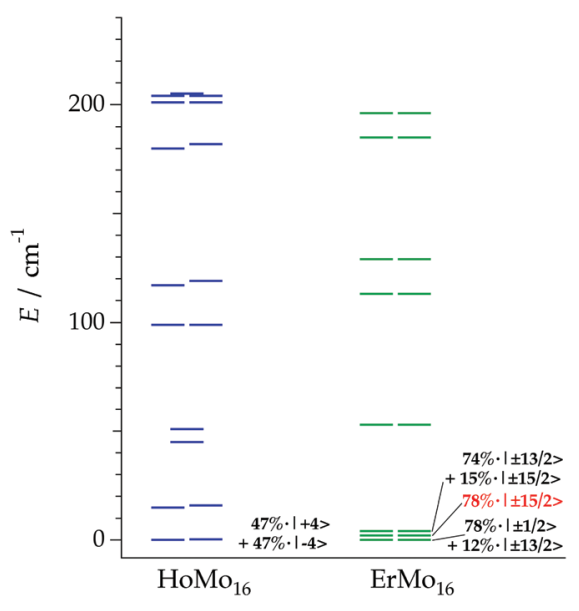

Fig. 4 Energy level scheme and main contributions to the ground state wave function for $\mathrm{HoMO}_{16}$ and $\mathrm{ErMo}_{16}$. 
effects over the chemical structure, while only slightly affecting the energy level description, ${ }^{47}$ are expected to become significant. This is expected to affect our modelling of the magnetization. As seen below, it is likely from the dynamic susceptibility behaviour that the Kramers doublet described by $78 \%$ of $\pm 15 / 2$ is the actual ground doublet. Within this assumption, the ground wave function would show a high $M_{J}$ projection compatible with SMM behaviour.

The ac magnetic susceptibilities were collected in the range 2-12 K with an applied alternating field of 3.95 Oe at different frequencies in the range 1-10000 $\mathrm{Hz}$. ErMo ${ }_{16}$ and $\mathrm{HoMo}_{16}$ show frequency dependent out-of-phase signals at very low temperatures. In neither complex a clear peak is observed (Fig. S2 and S3†) even under an external applied field of 1000 Oe. (Fig. 5 and 6) This feature is a characteristic of the fast relaxation process that takes place at low temperatures. In none of the other derivatives an increase in the out-of-phase signal down to $2 \mathrm{~K}$ was observed.
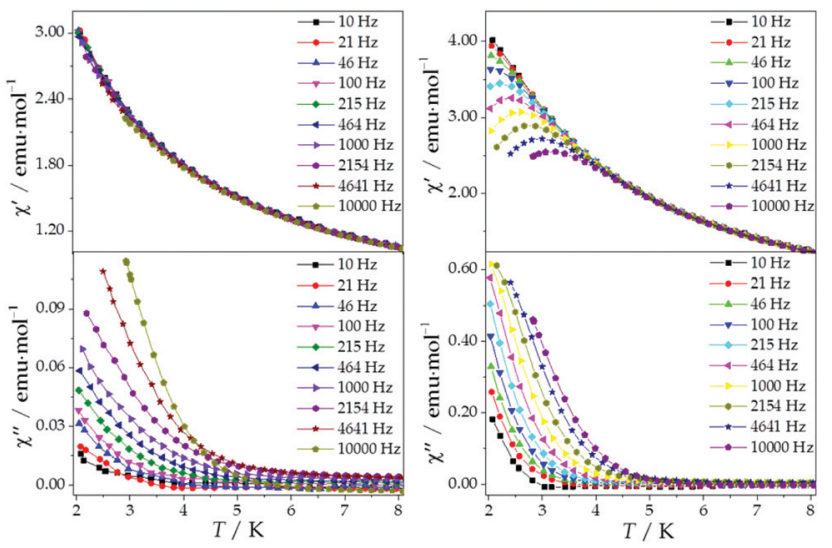

Fig. 5 In-phase (up) and out-of-phase (down) dynamic susceptibility of $\mathrm{HoMo}_{16}$ (left) and $\mathrm{ErMo}_{16}$ (right) with an applied field of 1000 Oe. The frequencies are shown in the legend. Solid lines are eye-guides.

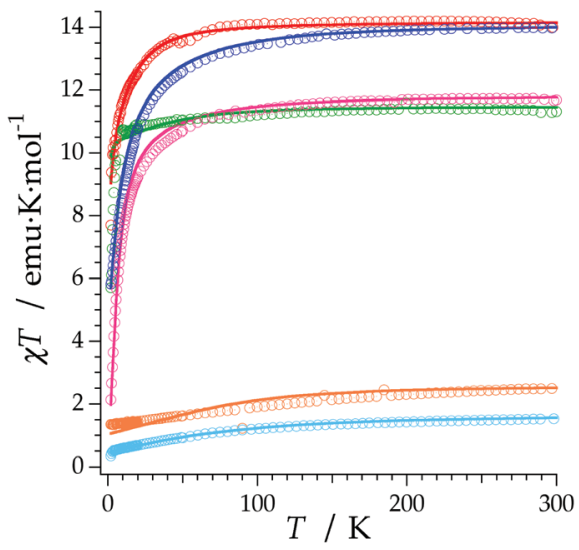

Fig. 6 Experimental (circles) and predicted (solid lines) $\chi^{T}$ product of the series $\mathrm{LnMo}_{10}$ under a magnetic field of $1000 \mathrm{Oe}: \mathrm{Dy}^{3+}$ (red), $\mathrm{Ho}^{3+}$ (blue), $\mathrm{Tb}^{3+}$ (pink), $\mathrm{Er}^{3+}$ (green), $\mathrm{Yb}^{3+}$ (orange), $\mathrm{Nd}^{3+}$ (clear blue) from 2 to $300 \mathrm{~K}$
LnMo $_{10}$ series. For this series our initial prediction, based on the coordination geometry around the lanthanoid, pointed towards the possibility of obtaining SMM behaviour in the Dy derivative ( $97 \%$ of $\left.M_{J}= \pm 11 / 2\right)$, in $\mathrm{Yb}\left(97 \%\right.$ of $\left.M_{J}= \pm 5 / 2\right)$ and in Er ( $99 \%$ of $\left.M_{J}= \pm 15 / 2\right)$ (see Experimental methods section). This was confirmed by the ac susceptibility data that showed slow relaxation of the magnetization in all three derivatives (Fig. 7, S4 and S5 $\dagger$ ).

The REC model permits to characterize the magnetic and spectroscopic properties of a family of complexes using a range of approaches. An extreme limit is the rough prediction with no free parameters, ${ }^{48}$ which allows the discovery of new SIMs. On the opposite extreme, one can perform an individual fit for each metal, which describes the observables more accurately but has a more reduced ability to extrapolate the results to related derivatives. In this case, we have decided to employ an intermediate path. Owing to the chemical similarity of the two families of polyoxomolybdates presented in this work, especially in the coordination environment, the product of the parameters $D_{\mathrm{r}}=0.72 \AA$ and $Z_{\mathrm{i}}=0.253$ obtained in the study of $\mathrm{LnMo}_{16}$ was used to reduce the number of independent REC parameters for each metal when modelling the magnetic properties of $\mathrm{LnMo}_{10}$. The magnetic susceptibility curves of this series were fitted individually keeping the relation $f=D_{\mathrm{r}} \cdot Z_{\mathrm{r}}$ constant, allowing just one free parameter per compound. The results are plotted in Fig. 6, where we can observe the excellent agreement between the model and the experiment. The sharp decrease that appears in $\mathrm{ErMo}_{10}$ below $10 \mathrm{~K}$ is reminiscent of the behavior previously observed at the same temperature range in other complexes, ${ }^{49,50}$ such as $\left[\operatorname{Er}(\mathrm{COT})_{2}\right]^{-}$, $\left[\mathrm{Er}\left(\mathrm{COT}^{\prime \prime}\right)_{2}\right]^{-}$and $\operatorname{Er}\left(\mathrm{Cp}^{*} \mathrm{COT}\right)$, where COT $=$ cyclooctatetraenyl dianion, COT $^{\prime \prime}=1$ 1,-bis-(trimethylsilyl) cyclooctatetraenyl dianion and $\mathrm{Cp}^{*}=$ pentamethylcyclopentadienide. As in the present case, in those examples the ground doublet can be characterized as an Ising state $\left(M_{J}= \pm 15 / 2\right)$, and this may favour a stronger dipolar interaction at low temperature. The
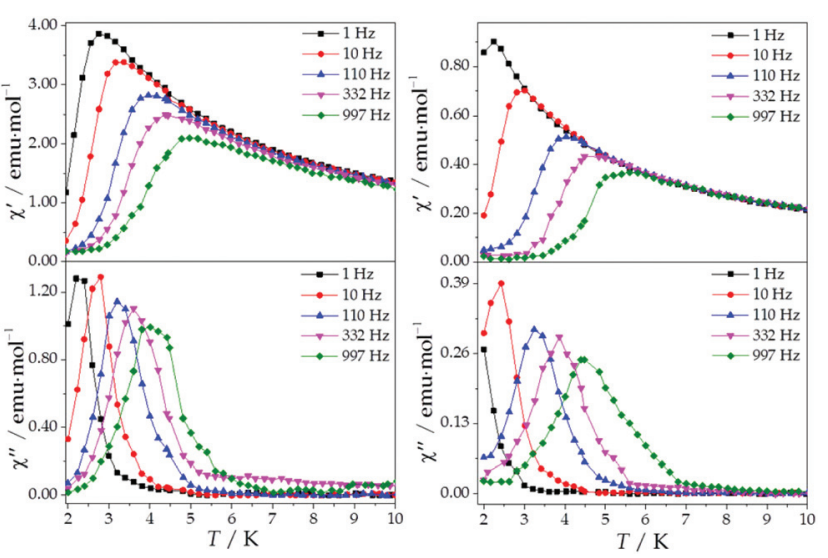

Fig. 7 In-phase (up) and out-of-phase (down) dynamic susceptibility of $\mathrm{DyMo}_{10}$ (left) and $\mathrm{YbMo}_{10}$ (right) under an applied field of 1000 Oe. The frequencies are shown in the legend. Solid lines are eye-guides. 
estimation of the energy levels (Fig. S8 $\dagger$ ) and wave functions of this new family of polyoxomolybdates are reported in the ESI. $\dagger$

An analysis of the frequency dependence of the $\chi^{\prime \prime}$ peaks through Arrhenius plots (Fig. S6 $\dagger$ ) has permitted to estimate the magnetization-relaxation parameters. Compared with analogous polyoxotungstates, polyoxomolybdates display poorer behaviour as SIMs. Out of the whole series, $\mathrm{Dy}^{3+}, \mathrm{Er}^{3+}$ and $\mathrm{Yb}^{3+}$ complexes can be characterised as SIMs (displaying clear peaks above $2 \mathrm{~K}$ ) and only under an external $d c$ field $\mathrm{H}=$ 1000 G. Under these conditions, a naïve fitting of the $a c$ data of the $\mathrm{Dy}^{3+}, \mathrm{Yb}^{3+}$ derivatives assuming an Orbach process would result in a barrier height $\left(U_{\text {eff }} / k_{\mathrm{B}}\right)$ of $38.5 \mathrm{~K}$ with a preexponential factor $\left(\tau_{0}\right)$ of $6.6 \times 10^{-8} \mathrm{~s}$ for the $\mathrm{Dy}^{3+}$ case and $23.3 \mathrm{~K}$ with $\tau_{0}=6.7 \times 10^{-6} \mathrm{~s}$ for the $\mathrm{Yb}^{3+}$ case, compared with the archetypical $\operatorname{ErW}_{10}\left(U_{\text {eff }} / k_{\mathrm{B}}\right)=55.2 \mathrm{~K}$ and $\tau_{0}=1.6 \times 10^{-8} \mathrm{~s}$. These plots do not contain enough information to independently fit a Raman process, but this should not be taken as a proof of an Orbach mechanism, especially lacking spectroscopic indication of levels at these energies. This is even more marked for the $\mathrm{Er}^{3+}$ derivative, which displays only two clear $\chi^{\prime \prime}$ peaks, precluding an Arrhenius fit.

The calculated energy level schemes for $\mathrm{DyMo}_{10}, \mathrm{ErMo}_{10}$ and $\mathrm{YbMo}_{10}$ are represented in Fig. 8. According to the individual magnetic susceptibility data fits based on the predictions of the REC model, $\mathrm{DyMo}_{10}$ possesses a ground state dominated by $M_{J}= \pm 11 / 2$ (86\%) with an excited state of $M_{J}=$ $0.92 \mid \pm 9 / 2>$, which is placed at about $11 \mathrm{~cm}^{-1}$ above it. Such scheme is compatible with the observed SMM behaviour. One can notice that in this example all the $M_{J}$ states are bunched below $100 \mathrm{~cm}^{-1}$ with the exception of the highest $M_{J}=15 / 2$ which is located at $260 \mathrm{~cm}^{-1}$. In $\mathrm{ErMo}_{10}$, the ground state is characterised by $99 \%$ of $M_{I}=15 / 2$ and the first excited Kramers doublet is placed at about $19 \mathrm{~cm}^{-1}$. In the case of $\mathrm{YbMo}_{10}$, the level scheme also supports the relationship between the ground-state wave function (described by $M_{J}=$ $97 \%$ of $\mid \pm 5 / 2>$ ) and the SMM behaviour. The rest of the energy levels appear at about $167 \mathrm{~cm}^{-1}$ above it, starting with the $M_{J}=$ $0.69 \mid \pm 3 / 2>$. The absence of mixing provides a quasi-pure

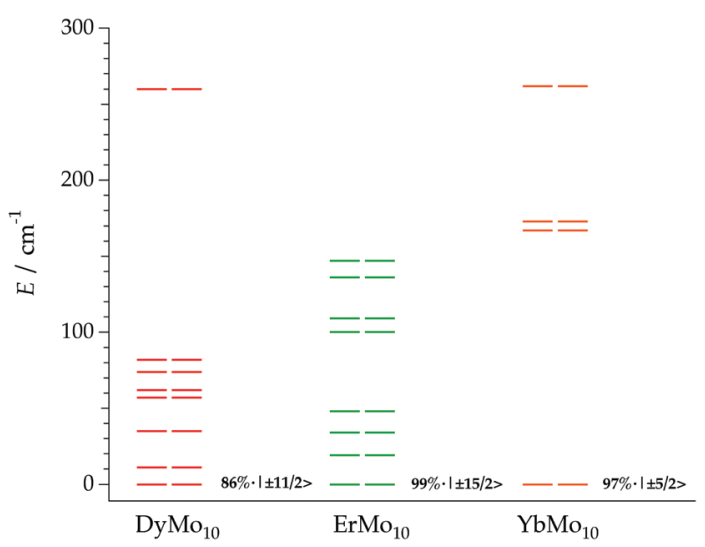

Fig. 8 Energy level scheme and main contributions to the ground state wave function for $\mathrm{DyMo}_{10}, \mathrm{ErMo}_{10}$ and $\mathrm{YbMo}_{10}$.
$M_{J}$ function in the ground state without a clear path to invert its moment, thus the magnetic moment may be blocked at low temperatures. Here one again needs to highlight the risk of an Orbach-only interpretation in absence of richer experimental information.

\section{Magneto-structural correlations}

The optimization of f-element single-molecule magnets is still an open problem. ${ }^{26}$ Thus, at this point, it is worth to briefly compare the results of a given lanthanide ion as a function of the different ligand fields created in the different families of POMs showing an approximate $D_{4 \mathrm{~d}}$ symmetry. For that, we will focus in the erbium analogue because its crystal structure has been determined for $\mathrm{ErW}_{10}, \mathrm{ErW}_{22}, \mathrm{ErMo}_{16}$ and $\mathrm{ErMo}_{10}$. Regarding the lowest energy levels, we found a ground state characterised by $\pm 13 / 2$ in both polyoxotungstates, and a first excited state dominated by $\pm 1 / 2$ (placed at about $16 \mathrm{~cm}^{-1}$ in $\mathrm{ErW}_{10}$ and $11 \mathrm{~cm}^{-1}$ in $\mathrm{ErW}_{22}$ ). In the case of $\mathrm{ErMo}_{10}$, the ground doublet is apparently dominated by $\pm 15 / 2$ (99\%) and the first excited state (located at about $19 \mathrm{~cm}^{-1}$ ) presents $85 \%$ of $\pm 1 / 2$, according to our theoretical calculations based on available susceptibility data. The explanation of such a different energy scheme can be attributed to differences in the first coordination sphere, as well as differences in the effective charges and distances of the oxygen donor atoms. Thus, while in the two polyoxotungstate series the interplanar distances, $d_{\mathrm{pp}}$, are equal to $2.46 \AA$ in $\mathrm{ErW}_{10}$ and $2.48 \AA$ in $\mathrm{ErW}_{22}$, in the $\mathrm{ErMo}_{10}$ this distance increases to a value of $2.61 \AA$. $\mathrm{ErMo}_{16}$ represents an intermediate situation, having $d_{\mathrm{pp}}=2.55 \AA$ and a skew angle comparable to that of $\operatorname{ErW}_{10}\left(44.2^{\circ}\right)$. In this case, these inexpensive calculations indicate that there are three Kramers doublets very close in energy, two of them dominated by high $M_{J}$ values and one dominated by $\pm 1 / 2$, being difficult to determine the true nature of the ground Kramers doublet.

\section{Conclusions}

In the last years, a sufficiently large set of lanthanoid-based SIMs has already been obtained. This has provided a good basis for relating their magnetic properties with the nature and structure of the coordination site around the lanthanide ion. A subsequent development that has been recently initiated is that related with the improvement in the chemical processability of these magnetic molecules in order to incorporate them into functional devices.

The present work contributes towards these two goals. Thus, we have used a robust family of ligands based on POMs to prepare new SIMs exhibiting SMM properties, which can be modelled using an effective crystal field approach previously developed for this kind of ligands. The key novelty has been the unprecedented use of polyoxomolybdates instead of polyoxotungstates for obtaining SIMs. While the chemistry of polyoxomolybdates is more challenging, this result has opened the possibility of making these magnetic molecules soluble in organic solvents, thus facilitating their processing and 
incorporation into devices. This contrasts with the SIMs based on polyoxotungstate ligands, which are commonly only soluble in water. Furthermore, we have also shown that polyoxomolybdate-based SIMs can be functionalised with organic groups, facilitating their processability -e.g. grafting onto surfaces/ electrodes - and the incorporation of a second property coming from the organic ligand. Last but not least, the enhanced reduction potential of polyoxomolybdates may also be of interest to incorporate delocalised electrons into the mixed-valence POM framework, thus increasing the interest of these magnetic molecules in spintronics. ${ }^{51-54}$

\section{Experimental methods}

All reagents and solvents used were commercially available. Acetonitrile was distilled under argon before use. The precursor for the $\mathrm{LnMo}_{16}$ series: $[\mathrm{TBA}]_{4}\left[\beta-\mathrm{Mo}_{8} \mathrm{O}_{26}\right]$, where TBA = $\left(n-\mathrm{C}_{4} \mathrm{H}_{9}\right)_{4} \mathrm{~N}$ was prepared according to a previously described literature procedure. ${ }^{55}$

The precursor $[\mathrm{TBA}]_{3}\left[\mathrm{Mo}_{6} \mathrm{O}_{18} \mathrm{NN}-\mathrm{C}_{6} \mathrm{H}_{4}-p-\mathrm{NO}_{2}\right]$ of the $\mathrm{LnMo}_{10}$ series was prepared as described elsewhere. ${ }^{56}$ The subsequent synthesis of the ligand $[\mathrm{TBA}]_{2}\left[\mathrm{Mo}_{5} \mathrm{O}_{13}(\mathrm{MeO})_{4}\left(\mathrm{NNC}_{6} \mathrm{H}_{4}-\right.\right.$ $\left.\left.p-\mathrm{NO}_{2}\right)\{\mathrm{Na}(\mathrm{MeOH})\}\right]$ was slightly modified from the initial report (see below). ${ }^{42}$

\section{Synthesis of $\mathrm{LnMo}_{16}$ series}

The salts $[\mathrm{TBA}]_{5}\left[\operatorname{Ln}\left(\beta-\mathrm{Mo}_{8} \mathrm{O}_{26}\right)_{2}\right]\left(\mathrm{Ln}^{\mathrm{III}}=\mathrm{Tb}, \mathrm{Dy}, \mathrm{Ho}, \mathrm{Er}, \mathrm{Tm}\right.$, and $\mathrm{Yb}$ ) were prepared following a slight modification of a previously described procedure. ${ }^{43}$ A solution of lanthanide salt $\mathrm{Ln}\left(\mathrm{NO}_{3}\right)_{3}(0.200 \mathrm{mmol})$ in $5 \mathrm{~mL}$ of acetonitrile was added drop-wise to a solution of $[\mathrm{TBA}]_{4}\left[\beta-\mathrm{Mo}_{8} \mathrm{O}_{26}\right](0.376 \mathrm{mmol})$ in $25 \mathrm{~mL}$ of acetonitrile under stirring. Then, $50 \mathrm{~mL}$ of diethyl ether were added carefully, in such a way that two layers were formed. After three days of slow diffusion, block-shaped crystals formed and were collected by filtration, washed with a small amount of acetonitrile, and dried under vacuum overnight (see ESI $\dagger$ for details of the elemental analysis and yield IR spectra).

\section{Synthesis of $\operatorname{LnMo}_{10}$ series}

Synthesis of the ligand $[\mathrm{TBA}]_{2}\left[\mathrm{Mo}_{5} \mathrm{O}_{13}(\mathrm{MeO})_{4}\left(\mathrm{NNC}_{6} \mathrm{H}_{4}-\boldsymbol{p}\right.\right.$ $\left.\left.\mathbf{N O}_{2}\right)\{\mathbf{N a}(\mathrm{MeOH})\}\right]$. $[\mathrm{TBA}]_{3}\left[\mathrm{Mo}_{6} \mathrm{O}_{18} \mathrm{NN}-\mathrm{C}_{6} \mathrm{H}_{4}-p-\mathrm{NO}_{2}\right](1.740 \mathrm{~g}$, $1.000 \mathrm{mmol}$ ) was introduced in $15 \mathrm{~mL}$ of methanol and $5 \mathrm{~mL}$ of $0.2 \mathrm{~mol} \mathrm{~L}^{-1}$ solution of $\mathrm{NaOH}$ in methanol $(1 \mathrm{mmol})$ was then added. The mixture was heated in refluxing methanol $\left(65^{\circ} \mathrm{C}\right)$ for 1 hour, leading to a red limpid solution. This solution was then allowed to cool to room temperature and filtered on a glass frit (por. 4). Diethyl-ether $(20 \mathrm{~mL})$ was added to the resulting filtrate, which was then placed at $-18{ }^{\circ} \mathrm{C}$ for one day. The red crystals thus obtained were filtered, rinsed with 3 portions of $5 \mathrm{~mL}$ of diethyl-ether and dried in air, yielding $1.200 \mathrm{~g}$ of $[\mathrm{TBA}]_{2}\left[\mathrm{Mo}_{5} \mathrm{O}_{13}(\mathrm{MeO})_{4}\left(\mathrm{NNC}_{6} \mathrm{H}_{4}-p-\mathrm{NO}_{2}\right)\{\mathrm{Na}(\mathrm{MeOH})\}\right]$.

Synthesis and crystallization of $\mathbf{L n M o}_{10}$ series. $[\mathrm{TBA}]_{2}\left[\mathrm{Mo}_{5} \mathrm{O}_{13}(\mathrm{MeO})_{4}\left(\mathrm{NNC}_{6} \mathrm{H}_{4}-p-\mathrm{NO}_{2}\right)\{\mathrm{Na}(\mathrm{MeOH})\}\right] \quad(0.376 \mathrm{~g}$, $0.250 \mathrm{mmol}$ ) was dissolved in $15 \mathrm{~mL}$ of methanol. $0.125 \mathrm{mmol}$ of the lanthanide salt $\left\{\mathrm{TbCl}_{3} \cdot 6 \mathrm{H}_{2} \mathrm{O}: 0.048 \mathrm{~g} ; \mathrm{ErCl}_{3} \cdot 6 \mathrm{H}_{2} \mathrm{O}\right.$ : $0.0342 \mathrm{~g} ; \mathrm{YbCl}_{3} \cdot 6 \mathrm{H}_{2} \mathrm{O}: 0.048 \mathrm{~g} ; \mathrm{Dy}\left(\mathrm{NO}_{3}\right)_{3} \cdot 5 \mathrm{H}_{2} \mathrm{O}: 0.048 \mathrm{~g}$; $\left.\mathrm{Nd}\left(\mathrm{NO}_{3}\right)_{3} \cdot 6 \mathrm{H}_{2} \mathrm{O}: 0.055 \mathrm{~g} ; \mathrm{Ho}\left(\mathrm{NO}_{3}\right)_{3} \cdot 5 \mathrm{H}_{2} \mathrm{O}: 0.055 \mathrm{~g}\right\}$ was then added. The resulting mixture was refluxed in methanol for $30 \mathrm{~min}$. The red/orange precipitate formed after cooling the solution to room temperature was filtered on a glass frit (por. 4) and washed twice with diethyl-ether. All compounds were recrystallised by slow diffusion of diethyl-ether in a solution in chloroform ( $c a .0 .300 \mathrm{~g}$ in $15 \mathrm{~mL}$ of $\mathrm{CHCl}_{3}$ ), leading to the formation of dark red crystalline materials with general formula $[\mathrm{TBA}]_{3}\left[\mathrm{Ln}\left\{\mathrm{Mo}_{5} \mathrm{O}_{13}(\mathrm{MeO})_{4} \mathrm{NNC}_{6} \mathrm{H}_{4}-p-\mathrm{NO}_{2}\right\}_{2}\right] \cdot 1.5 \mathrm{CHCl}_{3}$.

\section{Magnetic measurements}

Magnetic static and dynamic measurements of samples of $\mathrm{LnMo}_{16}$ and $\mathrm{LnMo}_{10}$ were performed by compacted powder molded from ground crystalline samples. Variable-temperature susceptibility measurements were carried out under a magnetic field of 1000 Oe in the temperature range 2-300 $\mathrm{K}$ on a magnetometer equipped with a SQUID sensor (Quantum Design MPMS-XL-5). The data were corrected for diamagnetic contribution from eicosane and for the diamagnetic contributions of the polyanions as deduced by using the Pascal's constant tables. Isothermal magnetization measurements at low temperature $(2 \mathrm{~K})$ were performed up to a field of $5 \mathrm{~T}$ in the same apparatus (see ESI $\dagger$ ).

\section{Ligand field calculations}

LnMo $_{16}$ series. The four magnetic susceptibility data of the $\mathrm{Tb}^{3+}, \mathrm{Dy}^{3+}, \mathrm{Ho}^{3+}$ and $\mathrm{Er}^{3+}$ polyanions were used to carry out a simultaneous fit of an effective ligand field hamiltonian. This was based on the Radial Effective Charge (REC) model, which uses effective point charges to model the ligand effects and thus estimate the crystal field parameters in mononuclear lanthanoid complexes (see details in ESI, $\dagger$ section 7). ${ }^{57}$ For this purpose we employed the SIMPRE package, a freely available fortran 77 code. ${ }^{58,59}$ This procedure provided the two parameters, namely the radial displacement and the effective charge, that can be used to describe the ligand field effects of the eight chemically equivalent oxygens of the polyoxomolybdate ligands. As a verification, the magnetic susceptibility of the two remaining members of the series $\left(\mathrm{Tm}^{3+}\right.$ and $\left.\mathrm{Yb}^{3+}\right)$ was predicted using the same parameters.

LnMo $_{10}$ series. At the time of our first contact with this family, we had not yet investigated the $\mathrm{LnMo}_{16}$ derivatives with the REC model, and thus we performed an initial (predictive) estimation to evaluate the likelihood of obtaining SMM behaviour in some of the derivatives of this series. For this purpose, we introduced the crystal structures of the $\mathrm{Tb}^{3+}, \mathrm{Ho}^{3+}$ and $\mathrm{Er}^{3+}$ derivatives as input in SIMPRE, applying the two REC parameters (radial displacement: $D_{\mathrm{r}}=0.895 \AA$ and effective charge: $\left.Z_{\mathrm{i}}=0.105\right)$ that had been determined for $\operatorname{LnW}_{10}$ and $\mathrm{LnW}_{22}$ in a previous work. ${ }^{45}$ On a second stage, we used the product of the radial displacement and the effective charge parameters obtained in the study of the series $\operatorname{LnMo}_{16}\left(f=D_{\mathrm{r}} \cdot Z_{\mathrm{i}}=0.18216\right)$ in order to fit the magnetic data of the series $\mathrm{LnMo}_{10}$ while 
keeping constant $f$, allowing only one free parameter per compound.

\section{Acknowledgements}

The present work has been funded by the EU (ERC Consolidator Grant DECRESIM, COST Actions CM1203 "Polyoxometalate Chemistry for Molecular Nanoscience, PoCheMon" and CA15128 Molecular Spintronics (MOLSPIN)), the Spanish MINECO (grant MAT2014-56143-R, CTQ201452758-P and Excellence Unit María de Maeztu MDM-20150538 granted to ICMol), and the Generalitat Valenciana (Prometeo Programme of Excellence). A. G.-A. acknowledges funding by the MINECO (Ramón y Cajal contract). E. C. and J. J. B. acknowledge the Blaise Pascal International Chair for financial support. S. C.-S. acknowledges the Generalitat Valenciana for a VALi+D postdoctoral grant. We thank J. M. Martínez-Agudo for performing the magnetic measurements.

\section{Notes and references}

1 S. A. Wolf, D. D. Awschalom, R. A. Buhrman, J. M. Daughton, S. Von Molnár, M. L. Roukes, A. Y. Chtchelkanova and D. M. Treger, Science, 2001, 294, 1488-1495.

2 M. E. Flatté, Nature, 2009, 462, 419-420.

3 J. Akerman, Science, 2005, 308, 508-510.

4 I. L. Prejbeanu, M. Kerekes, R. C. Sousa, H. Sibuet, O. Redon, B. Dieny and J. P. Nozières, J. Phys.: Condens. Matter, 2007, 19, 165218.

5 B. Georges, J. Grollier, M. Darques, V. Cros, C. Deranlot, B. Marcilhac, G. Faini and a. Fert, Phys. Rev. Lett., 2008, 101, 4-7.

6 J. R. Petta, A. C. A. Johnson, J. Taylor, E. A. Laird, A. Yacoby, M. D. Lukin, C. M. Marcus, M. Hanson and A. Gossard, Science, 2005, 309, 2180-2184.

7 J. F. Gregg, Nat. Mater., 2007, 6, 798-799.

8 K. L. Wang, I. Ovchinnikov, F. Xiu, A. Khitun and M. Bao, J. Nanosci. Nanotechnol., 2011, 11, 306-313.

9 A. R. Rocha, V. M. García-Suárez, S. W. Bailey, C. J. Lambert, J. Ferrer and S. Sanvito, Nat. Mater., 2005, 4, 335-339.

10 S. Sanvito, Nat. Phys., 2010, 6, 562-564.

11 J. Camarero and E. Coronado, J. Mater. Chem., 2009, 19, 1678-1684.

12 F. Prins, M. Monrabal-Capilla, E. A. Osorio, E. Coronado and H. S. J. Van Der Zant, Adv. Mater., 2011, 23, 1545-1549.

13 J. Dugay, M. Giménez-Marqués, T. Kozlova, H. W. Zandbergen, E. Coronado and H. S. J. Van Der Zant, Adv. Mater., 2015, 27, 1288-1293.

14 A. Holovchenko, J. Dugay, M. Giménez-Marqués, R. TorresCavanillas, E. Coronado and H. S. J. van der Zant, Adv. Mater., 2016, DOI: 10.1002/adma.201600890.
15 R. Sessoli, H. L. Tsai, A. R. Schake, S. Wang, J. B. Vincent, K. Folting, D. Gatteschi, G. Christou and D. N. Hendrickson, J. Am. Chem. Soc., 1993, 115, 1804-1816.

16 L. Bogani and W. Wernsdorfer, Nat. Mater., 2008, 7, 179186.

17 W. Wernsdorfer, Int. J. Nanotechnol., 2010, 7, 497-522.

18 E. Cremades, C. D. Pemmaraju, S. Sanvito and E. Ruiz, Nanoscale, 2013, 5, 4751-4757.

19 L. Thomas, F. Lionti, R. Ballou, D. Gatteschi, R. Sessoli and B. Barbara, Nature, 1996, 383, 145-147.

20 C. Paulsen, J.-G. Park, B. Barbara, R. Sessoli and A. Caneschi, J. Magn. Magn. Mater., 1995, 140-144, 18911892.

21 A. Ardavan and S. J. Blundell, J. Mater. Chem., 2009, 19, 1754-1760.

22 F. Troiani and M. Affronte, Chem. Soc. Rev., 2011, 40, 31193129.

23 P. C. E. Stamp and A. Gaita-Ariño, J. Mater. Chem., 2008, 19, $1718-1730$.

24 J. Lehmann, A. Gaita-Arino, E. Coronado and D. Loss, Nat. Nanotechnol., 2007, 2, 312-317.

25 D. N. Woodruff, R. E. P. Winpenny and R. A. Layfield, Chem. Rev., 2013, 113, 5110-5148.

26 S. T. Liddle and J. van Slageren, Chem. Soc. Rev., 2015, 44, 6655-6669.

27 N. Ishikawa, M. Sugita, T. Ishikawa, S. Y. Koshihara and Y. Kaizu, J. Am. Chem. Soc., 2003, 125, 8694-8695.

28 M. Urdampilleta, S. Klyatskaya, J.-P. Cleuziou, M. Ruben and W. Wernsdorfer, Nat. Mater., 2011, 10, 502-506.

29 M. Urdampilleta, S. Klayatskaya, M. Ruben and W. Wernsdorfer, ACS Nano, 2015, 9, 4458-4464.

30 S. Thiele, F. Balestro, R. Ballou, S. Klyatskaya, M. Ruben and W. Wernsdorfer, Science, 2014, 344, 1135-1138.

31 C. Wäckerlin, F. Donati, A. Singha, R. Baltic, S. Rusponi, K. Diller, F. Patthey, M. Pivetta, Y. Lan, S. Klyatskaya, M. Ruben, H. Brune and J. Dreiser, Adv. Mater., 2016, 28, 5195-5199.

32 A. Bedoya-Pinto, H. Prima-García, F. Casanova, E. Coronado and L. E. Hueso, Adv. Electron. Mater., 2015, 1500065.

33 J. J. Baldoví, S. Cardona-Serra, J. M. Clemente Juan, L. Escalera-Moreno, A. Gaita-Ariño and G. Mínguez Espallargas, Europhys. Lett., 2015, 110, 33001.

34 J. M. Clemente-Juan, E. Coronado and A. Gaita-Ariño, Chem. Soc. Rev., 2012, 41, 7464-7478.

35 N. V. Izarova and P. Kögerler, Polyoxometalate-based singlemolecule magnets, Trends in Polyoxometalates Research, 2015.

36 M. Vonci and C. Boskovic, Aust. J. Chem., 2014, 44, 66556669.

37 M. Shiddiq, D. Komijani, Y. Duan, A. Gaita-Ariño, E. Coronado and S. Hill, Nature, 2016, 531, 348-351.

38 J. J. Baldoví, S. Cardona-Serra, J. M. Clemente-Juan, E. Coronado, A. Gaita-Ariño and H. Prima-García, Chem. Commun., 2013, 49, 8922-8924.

39 S. Cardona-Serra, J. M. Clemente-Juan, E. Coronado, A. Gaita-Ariño, A. Camón, M. Evangelisti, F. Luis, 
M. J. Martínez-Pérez and J. Sesé, J. Am. Chem. Soc., 2012, 134, 14982-14990.

40 S. Sherif, G. Rubio-Bollinger, E. Pinilla-Cienfuegos, E. Coronado, J. C. Cuevas and N. Agraït, Nanotechnology, 2015, 26, 291001.

41 A. Kitamura, T. Ozeki and A. Yagasaki, Inorg. Chem., 1997, 36, 4275-4279.

42 C. Bustos, D. M.-L. Carey, K. Boubekeur, R. Thouvenot, A. Proust and P. Gouzerh, Inorg. Chim. Acta, 2010, 363, 4262-4268.

43 R. Villanneau, A. Proust, F. Robert and P. Gouzerh, Chem. Eur. J., 2003, 9, 1982-1990.

44 R. Villanneau, A. Proust, F. Robert and P. Gouzerh, J. Chem. Soc., Dalt. Trans., 1999, 421-426.

45 J. J. Baldoví, J. M. Clemente Juan, E. Coronado, Y. Duan, A. Gaita-Ariño and C. Giménez-Saiz, Inorg. Chem., 2014, 53, 9976-9980.

46 J. J. Baldoví, A. Gaita-Ariño and E. Coronado, Dalton Trans., 2015, 44, 12535-12538.

47 K. Qian, J. J. Baldoví, S.-D. Jiang, A. Gaita-Ariño, Y.-Q. Zhang, J. Overgaard, B.-W. Wang, E. Coronado and S. Gao, Chem. Sci., 2015, 6, 4587-4593.

48 J. J. Baldoví, Y. Duan, R. Morales, A. Gaita-Ariño, E. Ruiz and E. Coronado, Chem. - Eur. J., 2016, DOI: 10.1002/ chem.201601741.

49 K. R. Meihaus and J. R. Long, J. Am. Chem. Soc., 2013, 135, 17952-17957.
50 S. K. Singh, T. Gupta and G. Rajaraman, Inorg. Chem., 2014, 53, 10835-10845.

51 S. Cardona-Serra, J. M. Clemente-Juan, A. Gaita-Ariño, N. Suaud, O. Svoboda and E. Coronado, Chem. Commun., 2013, 49, 9621-9623.

52 S. Cardona-Serra, J. M. Clemente-Juan, E. Coronado, A. Gaita-Ariño, N. Suaud, O. Svoboda, R. Bastardis, N. Guihéry and J. J. Palacios, Chem. - Eur. J., 2015, 21, 763769.

53 C. Bosch-Serrano, J. M. Clemente-Juan, E. Coronado, A. Gaita-Ariño, A. Palii and B. Tsukerblat, ChemPhysChem, 2012, 13, 2662-2665.

54 C. Bosch-Serrano, J. M. Clemente-Juan, E. Coronado, A. Gaita-Ariño, A. Palii and B. Tsukerblat, Phys. Rev. B: Condens. Matter Mater. Phys., 2012, 86, 024432.

55 W. Klemperer, Inorg. Synth., 2007, 27, 74-85.

56 C. Bustos, B. Hasenknopf, R. Thouvenot, J. Vaissermann, A. Proust and P. Gouzerh, Eur. J. Inorg. Chem., 2003, 15, 2757-2766.

57 J. J. Baldoví, J. J. Borrás-Almenar, J. M. Clemente-Juan, E. Coronado and A. Gaita-Ariño, Dalton Trans., 2012, 41, 13705.

58 J. J. Baldoví, S. Cardona-Serra, J. M. Clemente-Juan, E. Coronado, A. Gaita-Ariño and A. Palii, J. Comput. Chem., 2013, 34, 1961-1967.

59 J. J. Baldoví, J. M. Clemente-Juan, E. Coronado, A. GaitaAriño and A. Palii, J. Comput. Chem., 2014, 35, 1930-1934. 